\title{
Anti-tissue transglutaminase antibodies (IgA and IgG) in both Crohn's disease and autoimmune diabetes
}

\author{
Virgínia Lúcia Ribeiro-Cabral ${ }^{1}$, Francy Reis da-Silva-Patrício ${ }^{2}$, Orlando Ambrogini-Junior ${ }^{1}$ \\ and Sender Jankiel-Miszputen ${ }^{1}$
}

${ }^{1}$ Department of Internal Medicine. Division of Gastroenterology. ${ }^{2}$ Department of Pathology. Division of Pediatric. Federal University of São Paulo. São Paulo, Brazil

\begin{abstract}
Objective: a strong association has been observed between celiac disease, generally its silent clinical form, and autoimmune disorders. A potential correlation with inflammatory bowel disease has also been suggested. Anti-tissue transglutaminase antibodies have been detected in Crohn's disease. We investigated the prevalence of celiac disease in patients with autoimmune diabetes and in Crohn's disease patients and also evaluated the correlation between anti-transglutaminase antibody positivity and the clinical status of these diseases.

Methods: anti-tissue transglutaminase and anti-endomysium antibodies were assessed by enzyme-linked immunosorbent assay and indirect immunofluorescence, respectively. Upper digestive endoscopy and duodenal biopsy were indicated for cases with positive serology.

Results: anti-transglutaminase antibodies were detected in five diabetic patients (prevalence of $11.1 \%$ ), only one serum sample was positive for IgG isotypes. Nine of thirty-three patients with Crohn's disease had low positive levels for IgA anti-transglutaminase. Antiendomysium antibodies were detected only in celiac patients. Celiac disease was confirmed in all diabetic patients submitted to duodenal biopsies who presented both anti-transglutaminase and anti-endomisyum antibodies positivity. In Crohn's disease, its clinical status and the diagnosis of celiac disease were not associated with positive anti-transglutaminase result.

Conclusions: the prevalence of celiac disease was high in diabetic patients. Anti-tissue transglutaminase antibodies were sensitive and specific markers of celiac disease in this diabetic group, while these antibodies were of limited value for celiac disease screening in patients with Crohn's disease.
\end{abstract}

Key words: Anti-tissue transglutaminase. Celiac disease. Crohn's disease. Diabetes mellitus.

Received: 14-02-11.

Accepted: 14-04-11.

Correspondence: Virgínia Lúcia Ribeiro Cabral.

e-mail: virginiacabral@terra.com.br
Ribeiro-Cabral VL, da-Silva-Patrício FR, Ambrogini-Junior O, Jankiel-Miszputen S. Anti-tissue transglutaminase antibodies (IgA and IgG) in both Crohn's disease and autoimmune diabetes. Rev Esp Enferm Dig 2011; 103: 453-457.

\section{INTRODUCTION}

Celiac disease is an enteropathy that is triggered by an environmental stimulus (gluten) in individuals with a genetic predisposition. The histological and clinical characteristics of celiac disease are defined by the intensity of the immune response which, in turn, is influenced by the interaction between the environmental factor and genetic background $(1,2)$.

The advent of sensitive and specific serological tests has facilitated the diagnosis of celiac disease and its atypical clinical forms, and even the identification of asymptomatic individuals $(3,4)$. A strong association has been observed between celiac disease, generally its silent clinical form, and autoimmune disorders (5). Studies have shown that inflammatory bowel disease is more common in celiac patients than in the general population $(6,7)$, although some researchers have contested this affirmation. The contradictory results were attributed to genetic background and/or environmental factors (8).

Anti-endomysium antibodies are a specific marker of celiac disease. Since transglutaminase has been recognized as the main antigen of anti-endomysium antibodies (9), tests have been developed for the detection of anti-tissue transglutaminase (anti-tTG) antibodies. These tests were found to be highly sensitive for the diagnosis of celiac disease. However, a high rate of false-positive results has been reported. The use of purified or recombinant human antigen has improved the specificity of the test $(10,11)$. Transglutaminase is a multifunctional protein normally expressed in endothelial cells, smooth muscle cells and mesangial 
cells. This enzyme plays an important role in apoptosis and has been reported to be actively involved in the wound healing process $(12,13)$.

Anti-tTG antibodies have been identified in inflammatory bowel disease, suggesting a low specificity of these antibodies for the diagnosis of celiac disease. This observation was attributed to tissue lesions or to the inflammatory activity presented in patients with inflammatory bowel disease $(14,15)$.

IgG antibodies against tTG have been detected in autoimmune diseases not associated with celiac disease $(16,17)$.

Based on the hypothesis that celiac disease is associated with autoimmune diabetes and Crohn's disease or that the occurrence of anti-tTG antibodies, especially IgG, is triggered by an autoimmune condition, we assessed IgA and IgG anti-tTG antibodies using specific human tTG antigen. The focus this study was the diagnosis of celiac disease in patients with autoimmune diabetes and in a group of patients with Crohn's disease. We also evaluated the correlation between anti-tTG positivity and the clinical status of these diseases in those patients whose celiac disease was not diagnosed.

\section{PATIENTS AND METHODS}

\section{Patients}

The study was approved by the Ethics Committee of our institution and informed consent was obtained from all patients.

Celiac disease was investigated in 45 consecutively selected patients with autoimmune diabetes (18). Twentyfour of the patients were female, the median age was 18 years (range: 14 to 26), and the median duration of diabetes was 8 years (range: 1 to 14 ).

Thirty-three patients with Crohn's disease were diagnosed according to clinical, radiological, endoscopic and morphological criteria. Eighteen women and 15 men with a median age of 42 years (range: 18-72) and a disease duration of 9 years (range: 1-24) were studied. Inflammatory activity was assessed using the Harvey-Bradshaw simple clinical index (19) and by laboratorial tests (serum albumin) (20). Disease location and behavior were classified according to the Montreal classification for Crohn's disease (21).

\section{Serological tests}

The patients were submitted to the investigation of antihuman tTG (IgA and $\operatorname{IgG}$ ) and anti-endomysial (IgA) antibodies. All serum samples were tested in duplicate. IgA and IgG anti-human tTG antibodies were measured by enzyme-linked immunosorbent assay using a commercial kit (Quanta Lite ${ }^{\mathrm{TM}}$, Inova Diagnostics, Inc., San Diego, CA, USA) according to manufacturer instructions. Absorbance was read at $450 \mathrm{~nm}$. Antibody titers $>20$ arbitrary units
$(\mathrm{AU}) / \mathrm{mL}$ were defined as positive. IgA anti-endomysial antibodies were detected by indirect immunofluorescence using monkey esophagus as substrate $\left(\mathrm{ImmuGlo}^{\mathrm{TM}} \mathrm{kit}\right.$, Immco Diagnostics, Buffalo, NY, USA) according to manufacturer instructions. A titer $>1: 10$ was considered to be positive.

\section{Upper digestive endoscopy and histological analysis}

Upper digestive endoscopy and duodenal biopsy were indicated for cases presenting positive serology. Excluded from this phase of the study were diabetic patients with autonomic neuropathy and patients regularly taking nonsteroidal anti-inflammatory drugs.

Biopsies were obtained from the distal duodenum, fixed in $10 \%$ formalin, processed for paraffin embedding, and stained with hematoxylin-eosin. All slides were examined under a light microscope at 400X magnification under the supervision of an experienced pathologist in the diagnosis of celiac disease.

The number of intraepithelial lymphocytes (IELs) and epithelial cell nuclei was counted in an uninterrupted sequence of superficial epithelium, for a total of 300 epithelial cells. The number of lymphocytes found, excluding those crossing the basement membrane, was expressed as the proportion per 100 epithelial cells. Infiltrative lesion (type 1 lesion) was defined as IELs density higher than 30 lymphocytes/100 epithelial cells.

The histological alterations observed in the duodenal mucosa that corresponding to those described for celiac disease were classified according to the criteria adopted by the North American Society for Pediatric Gastroenterology, Hepatology and Nutrition and by the Working Group of the United European Gastroenterology Week $(22,23)$.

\section{Statistical analysis}

Data are expressed as mean or median and range. Quantitative variables were compared by the Mann-Whitney U test. Differences in the distribution of categorical data were compared using the chi-square test or Fisher's exact test, when required. A $p$ value $<0.05$ was considered to be statistically significant.

\section{RESULTS}

All patients ingested gluten regularly.

\section{Serological tests}

Anti-tTG antibodies (IgA) were detected in four diabetic patients, with a median titer of $95.9 \mathrm{AU} / \mathrm{mL}$ (48.3 to 130). These cases also tested positive for anti-endomysial anti- 


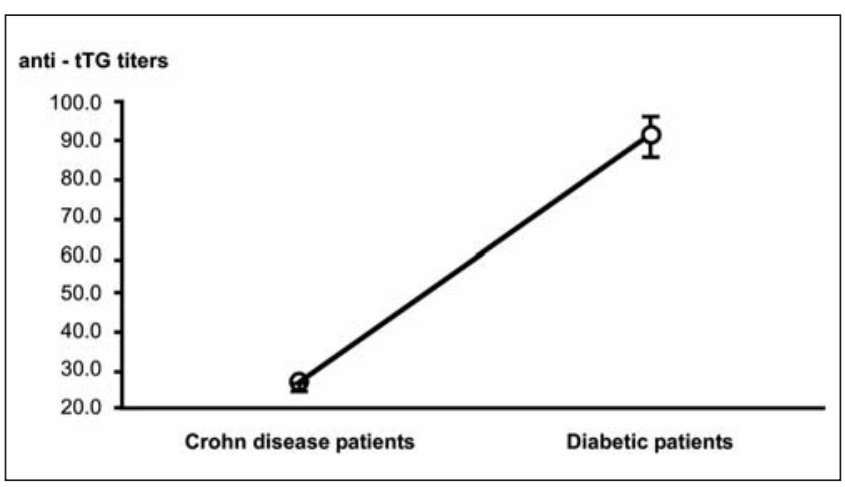

Fig. 1. Serum anti-tissue transglutaminase concentrations in diabetic patients with celiac disease and in patients with Crohn's disease $(p=0.003$, Mann Whitney test)

bodies, with a median titer of 1:40 (1:40 to $1: 240)$. Only one serum sample was positive for IgG anti-tTG, with a titer of $85.5 \mathrm{AU} / \mathrm{mL}$. This sample belonged to a diabetic patient who was IgA deficient (serum level $<7 \mathrm{mg} / \mathrm{dL}$ ).

Nine of the 33 patients with Crohn's disease were positive for IgA anti-tTG antibodies, with a mean titer of 25.54 $\pm 5.23 \mathrm{AU} / \mathrm{mL}$ (Fig. 1). Anti-endomysial antibodies were not detected in any of these patients. Two serum samples presented homogeneous fluorescence of the whole myofibril, suggesting the presence of smooth muscle antibodies at low levels.

\section{Upper digestive endoscopy and histological analysis}

Fourteen subjects were selected for upper digestive endoscopy. Three of the Crohn's disease patients refused to undergo the procedure and were excluded from the study.

All diabetic patients who were submitted to endoscopy presented histological alterations compatible with those described for celiac disease and received a gluten-free diet. The mean density of IELs in the duodenal biopsies of these patients was $50.8 \pm 18.14$ lymphocytes/100 epithelial cells.

The duodenal biopsies of Crohn's disease patients showed a preserved villous architecture. The mean density of IELs was $12.17 \pm 6.59$ lymphocytes/100 epithelial cells and this was significantly different from that of celiac diabetic patients $(\mathrm{p}=0.04)$.

No association was observed between anti-tTG positivity and clinical status of the Crohn disease (Tables I and II).

\section{DISCUSSION}

Transglutaminase is an enzyme widely found in human organs, which is involved in various physiological processes such as extracellular matrix formation, apoptosis and intestinal mucosal healing $(13,24)$.

Type 1 diabetes mellitus is an organ-specific autoimmune disease resulting from the destruction of insulin-producing
Table I. Anti-transglutaminase profile according demographic and clinical features of Crohn disease patients

\begin{tabular}{|c|c|c|c|}
\hline \multirow[t]{2}{*}{ Patients characteristics } & \multicolumn{2}{|c|}{ Anti-tTG } & \multirow[t]{2}{*}{$p$} \\
\hline & positive & negative & \\
\hline Gender (F/M) & $4 / 2$ & $13 / 11$ & 0.665 \\
\hline Disease duration (years)* & 10 & 9 & 0.840 \\
\hline Albumin levels $(\mathrm{g} / \mathrm{dL})^{*}$ & 4.6 & 4.5 & 0.813 \\
\hline Inflammatory activity & & & 0.309 \\
\hline Active & 3 & 6 & \\
\hline Inactive & 3 & 18 & \\
\hline Tabagism (y/n) & $1 / 5$ & $4 / 20$ & 1.0 \\
\hline
\end{tabular}

*median. F: female; M: male; y: yes; n: no.

pancreatic beta cells. Glutamic acid decarboxylase $\left(\mathrm{GAD}_{65}\right)$ is a beta-cell autoantigen. T cells have been shown to play a critical role in the destruction of beta cells, with the content of apoptotic bodies coming in contact with the immune system, which leads to an autoimmune response (25). We used autoantibodies to anti-GAD $\mathrm{GS}_{65}$ as a marker of autoimmunity in the type 1 diabetic patients studied here. No association was observed between the presence of the $\mathrm{GADA}_{65}$ and anti-tTG positivity (data not shown).

We found a significant increase in anti-tTG titers in diabetic patients with diagnosis of celiac disease. The absence of anti-tTG antibodies in autoimmune diabetes not associated with celiac disease suggests that its positivity in celiac diabetic patients is a fact that may not be related to autoimmunity alone.

In celiac disease, the sensitivity of IgG anti-tTG antibodies is close to $100 \%$ in IgA-deficient patients (26). In the present study, the only serum sample that tested positive for these antibodies belonged to a celiac patient with IgA deficiency.

Table II. Anti-transglutaminase profile according Montreal classification for Crohn's disease patients that undergone duodenal biopsies

\begin{tabular}{llll}
\hline & \multicolumn{2}{c}{ Anti-tTG } & $p$ \\
& positive & negative & \\
\hline Age at diagnosis (yr) & & & 0.290 \\
Below 16 & None & 3 & \\
Between 17 and 40 & 5 & 14 & \\
Above 40 & 1 & 7 & 0.213 \\
Location & & & \\
L1 & None & 12 & \\
L2 & 2 & 5 & 0.375 \\
L3 & 4 & 7 & \\
Behavior & & & \\
B1 & 1 & 11 & \\
B2 & 1 & 4 & \\
B3 & 4 & 9 & \\
\hline
\end{tabular}


We observed low positive levels of anti-tTG (IgA) in patients with Crohn's disease, whose duodenal biopsies showed a preserved villous architecture. Several studies have shown that the prevalence and serum levels of antitTG antibodies depend on the degree of histological damage in celiac disease $(27,28)$. It is possible that the presence of severe villous atrophy had been responsible for the higher serum anti-tTG titers observed in diabetic celiac patients when compared to Crohn's disease patients.

Large numbers of villous IELs was described during an episode of active Crohn's enteritis (29). However, Wright et al. (30) found a similar IEL density in the duodenum of Crohn's disease patients with normal radiographic and endoscopic findings in agreement with our results.

Di Tola et al. (15) reported a relationship between antitTG positivity and Crohn's disease activity, although the degree of intestinal damage had not been described. No such relationship was demonstrated in the present study. This discrepancy might be due to differences in the criteria used to define inflammatory activity in Crohn's disease or in the histopathological features.

Complications of diabetes mellitus such as autonomic neuropathy classically occur in patients with long-term disease. The knowledge that the presence of this motor disorder may favor the occurrence of an inflammatory process in the intestinal mucosa (31) led us to study patients with recent-onset diabetes. The Crohn's disease patients in our study were older than the diabetic ones. However, this demographic characteristic did not interfere with the present results since anti-tTG antibodies have not been reported to be related to age in adolescent and adult patients (32).

Farrace et al. (14) demonstrated that tTG is released by fibroblasts into the extracellular matrix in the intestine of celiac patients. In the present study, anti-endomysial antibodies were only detected in patients with celiac disease. However, a homogeneous intracellular fluorescence pattern was observed in two patients with Crohn's disease.

Antibodies reacting with components of the cytoskeleton have been described in patients with inflammatory bowel disease (33) and celiac disease. Pedreira et al. (34) found an association between the presence of these antibodies and the severity of gut injury in celiac patients. The identification of cytoplasmic actin as an abundant glutaminyl substrate for tTG in leukemia -derived human cell lines undergoing apoptosis (35) suggests that intracellular transglutaminase might be the antigen related to this fluorescence pattern. Thus, the presence of anti-smooth muscle antibodies and anti-endomysium antibodies might indicate a distinct antigenic expression patterns for tTG. Villous atrophy might be necessary to trigger an increase of anti-tTG antibody titers and the appearance of anti-endomysin in these diseases. Further studies are still needed to investigate the relationship between anti-tTG antibodies and duodenal villous atrophy in Crohn's disease in order to determine whether this pattern of tissue injury is responsible for the elevated titers of these antibodies.

\section{ACKNOWLEDGMENTS}

We thank Dr. Sérgio Atala Dib and Dr. Mônica Andrade Lima Gabbay for assistance in our study.

\section{REFERENCES}

1. American Gastroenterological Association: AGA Medical Position Statement: celiac sprue. Gastroenterology 2001;120:1522- 5.

2. Kagnoff MF. Overview and pathogenesis of celiac disease. Gastroenterology 2005;128:S10- 8 .

3. Rodrigo-Sáez L, Pérez-Martínez I. Adult celiac disease - a common, significant health problem worldwide. Rev Esp Enferm Dig 2010;102 (8):461-5.

4. Rostom A, Murray JA, Kagnoff M. American Gastroenterological Association (AGA) Institute Technical Review on the Diagnosis and Management of Celiac Disease. Gastroenterology 2006;131:1981-2002.

5. Neuhausen SL, Steele L, Ryan S, Mousavi M, Pinto M, Osann KE, et al. Co- occurrence of celiac disease and other autoimmune diseases in celiacs and their first-degree relatives. J Autoimmun 2008;31(2):1605.

6. Tursi A, Giorgetti GM, Brandimarte G, Elisei W. High prevalence of celiac disease among patients affected by Crohn's disease. Inflamm Bowel Dis 2005;11:662-6.

7. Yang A, Chen Y, Scherl E, Neugut AI, Bhagat G, Green PHR. Inflammatory bowel disease in patients with celiac disease. Inflamm Bowel Dis 2005; 11:528-32.

8. Mantzaris GJ, Roussos A, Koilakou S, Petraki K, Rontogianni D, Tsirogianni A, et al. Prevalence of celiac disease in patients with Crohn's disease. Inflamm Bowel Dis 2005;11:1029.

9. Dieterich W, Ehnis T, Bauer M, Donner P, Volta U, Riecken EO, et al. Identification of tissue transglutaminase as the autoantigen of celiac disease. Nat Med 1997;3:797-801.

10. Wong RCW, Wilson RJ, Steele RH, Radford-Smith G, Adelstein S. A comparison of 13 guinea pig and human anti-tissue transglutaminase antibody ELISA Kits. J Clin Pathol 2002;55:488-94.

11. Li M, Yu L, Tiberti C, Bonamico M, Taki I, Miao D, et al. A Report on the International Transglutaminase Autoantibody Workshop for Celiac Disease. Am J Gastroenterol 2009;104:154-63.

12. Piacentini M. Tissue transglutaminase: a candidate effector element of physiological cell death. Curr Top Microbiol Immunol 1995;200:16375 .

13. Telci D, Griffin M. Tissue transglutaminase (TG2) - a wound response enzyme. Front Biosci 2006;11:867-82.

14. Farrace MG, Picarelli A, Di Tola M, Sabbatella L, Marchione OP, Ippolito G, et al. Presence of anti-"tissue" transglutaminase antibodies in inflammatory intestinal disease: an apoptosis -associated event? Cell Death Diff 2001;8:767-70.

15. Di Tola M, Sabbatella L, Anamia MC, Viscido A, Caprilli R, Pica R, et al. Anti-tissue transglutaminase antibodies in inflammatory bowel disease: new evidence. Clin Chem Med 2004;42(10):1092-7.

16. Van der Sluijs Veer G, Vermes I. IgG autoantibodies against tissue transglutaminase in relation to antinuclear antibodies. Clin Chem 2001;47:952-4.

17. Atzeni F, Doria A, Ghirardello A, Villalta D, Zampieri S, Carrabba M, et al. Organ-specific autoantibodies in patients with rheumatoid arthritis treated with adalimumab: a long-term follow-up prospective. Autoimmunity 2008;41(1):87-91.

18. American Diabetes Association. Diagnosis and classification of diabetes mellitus. Diabetes Care 2005;28(1):S37- 42.

19. Harvey RF, Bradshaw JM. A simple index of Crohn's disease activity. Lancet 1980;8:514.

20. Cabral VLR, Carvalho L, Miszputen SJ. Importance of serum albumin values in both nutritional and inflammatory activity assessment in patients with Crohn's disease. Arq Gastroenterol 2001;38(2):104-8.

21. Satsangi J, Silverberg S, Vermeire S, Colombel J-F. The Montreal classification of inflammatory bowel disease: controversies, consensus and implications. Gut 2006;55:749-53.

22. Hill ID, Dirks MH, Liptak GS, Colletti RB, Fasano A, Guandalini S, et al. Guideline for the diagnosis and treatment of celiac disease in chil- 
dren: Recommendations of the North American Society for Pediatric Gastroenterology, Hepatology and Nutrition. J Pediatr Gastroenterol Nutr 2004;40(1):1-19.

23. Working group of the United European Gastroenterology. When is a celiac a celiac? Eur J Gastroenterol Hepatol 2001;13:1123-8.

24. Lorand L, Graham RM. Transglutaminases: crosslinking enzymes with pleiotropic functions. Nature 2003;4:140-56.

25. Yoon JW, Jun HS. Cellular and molecular pathogenic mechanisms of insulin-dependent diabetes mellitus. Ann NY Acad Sci 2001;928:200-11.

26. Korponay-Szabo IR, Dahlbom I, Laurila K, Koskinen S, Woolley N, Partanen J, et al. Elevation of IgG antibodies against tissue transglutaminase as a diagnostic tool for coeliac disease in selective IgA deficiency. Gut 2003;52:1567-71.

27. Fabiani E, Catasi C, International Working Group on Eu-tTG. The serum IgA class anti-tissue transglutaminase antibodies in the diagnosis and follow-up of celiac disease. Results of an international multi-centre study. Eur J Gastroenterol Hepatol 2001;13:659-65.

28. Tursi A, Brandimarte G, Giorgetti GM. Prevalence of anti-tissue transglutaminase antibodies in different degrees of intestinal damage in celiac disease. J Clin Gastroenterol 2003;36(3):219- 21.
29. Chang F, Mahadeva U, Deere H. Pathological and clinical significance of increased intraepithelial lymphocytes (IELs) in small bowel mucosa. APMIS 2005;113:385-99.

30. Wright CL, Riddell RH. Histology of the stomach and duodenum in Crohn's disease. Am J Surg Pathol 1998;22(4):383-90.

31. Zietz B, Lock G, Straub RH, Braun B, Schölmerich J, Palitzsch K-D. Small-Bowel overgrowth in diabetic subjects is associated with cardiovascular autonomic neuropathy. Diabetes Care 2000;23(8):1200-1

32. Leffler DA, Schuppan D. Update on serologic testing in celiac disease. Am J Gastroenterol 2010;105:2520-4

33. Zauli D, Crespi C, Dall'Amore P, Bianchi FB, Pisi E. Antibodies to the cytoskeleton components and other autoantibodies in inflammatory bowel disease. Digestion 1985;32:140-4.

34. Pedreira S, Sugai E, Moreno ML, Vázquez H, Niveloni S, Smecuol E, et al. Significance of smooth muscle/anti-actin autoantibodies in celiac disease. Acta Gastroenterol Latino Am 2005;35:83-93.

35. Nemes Z Jr, Adany R, Balazs M, Boross P, Fésüs L. Identification of cytoplasmic actin as an abundant glutaminyl substrate for tissue transglutaminase in HL-60 and U937 cells undergoing apoptosis. J Biol Chem 1997;272:20577-83. 